\title{
Liver injury in COVID-19: clinical features and treatment management
}

\author{
Dongdong Yu ${ }^{1 \dagger}$, Qingru Du ${ }^{2,9 \dagger}$, Shengguang Yan ${ }^{3 \dagger}$, Xu-Guang Guo ${ }^{4}$, Yehao He ${ }^{5}$, Guodong Zhu ${ }^{6,7}$, \\ Kewei Zhao ${ }^{8}$ and Shi Ouyang ${ }^{2^{*}}$ (D)
}

\begin{abstract}
Severe acute respiratory syndrome coronavirus-2 (SARS-CoV-2) has spread to many countries around the world. In addition to lung disease, severe cases also displayed varying degrees of liver injury. This article will describe the latest developments regarding coronavirus and the pathogenesis of liver injury, the prone population and clinical characteristics of these patients, as well as providing some suggestions for clinical treatment.
\end{abstract}

Keywords: COVID-19, SARS-CoV2, Liver injury

\section{Background}

Since December 2019, severe acute respiratory syndrome coronavirus-2(SARS-CoV-2), named by the International Classification Committee of viruses, has brought new health threats and challenges to the world. In March 11, 2020, the coronavirus disease 2019(COVID-19) was declared a global pandemic by WHO. As of March 8, 2021, there have been $156,496,592$ confirmed cases of COVID-19 worldwide, including 3,264,143 deaths, which were reported to WHO. Abnormal liver function is often found in patients with COVID-19, and some studies [1] have shown that SARS-COV-2 is associated with liver dysfunction or damage. In China, there are 300 million patients with chronic liver disease, so clinicians should be alert to the possibility of liver injury in COVID-19 patients.

\footnotetext{
*Correspondence: ouyangshi@gzhmu.edu.cn

${ }^{\dagger}$ Dongdong Yu, Qingru Du and Shengguang Yan are co-first authors and contributed equally to this work

${ }^{2}$ Department of Infection Disease, The Fifth Affiliated Hospital of Guangzhou Medical University Guangzhou, Guangzhou 510150, China Full list of author information is available at the end of the article
}

\section{Occurrence of liver injury in COVID-19 Incidence of liver injury}

The largest cohort study in China [2] included 1,099 patients with COVID-19, of whom 21 (2.1\%) had hepatitis B, $21.3 \%$ and $22.2 \%$ had elevated Alanine Amino Transaminase (ALT) and Aspartate Amino Transaminase (AST), and $10.5 \%$ had abnormal bilirubin. Cai [3] et al. analyzed 417 patients with COVID-19 in Shenzhen. The standards of abnormal liver function are: ALT $>40 \mathrm{U} / \mathrm{L}$, AST $>40 \mathrm{U} / \mathrm{L}, \mathrm{GGT}>49 \mathrm{U} / \mathrm{L}, \mathrm{ALP}>135 \mathrm{U} / \mathrm{L}$, and total bilirubin (TBIL) $>17.1 \mathrm{mmol} / \mathrm{L}$ [3]. COVID-19 associated hepatic injury should be defined as ALT or AST exceeding 3 times the upper limit of the normal value, and ALP, GGT or TBIL exceeding 2 times the upper limit of the normal value [3]. In order to further describe the liver injury, it is also classified as hepatocellular, cholestatic and mixed type. Patients with elevated ALT and/or AST more than 3 times the upper limit of normal (ULN) are classified as hepatocyte type; Patients with raised ALP or GGT twice the ULN are classified as cholestatic type, and mixed type patients have both (see Table 1). COVID-19 was classified into mild and severe cases according to National Health Commission of the People's Republic of China Handbook of Prevention and Treatment of the Pneumonia Caused by the Novel Coronavirus (2019-nCoV) (in Chinese) 2020 (see Table 1) [4]. The

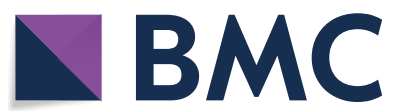

(c) The Author(s) 2021. Open Access This article is licensed under a Creative Commons Attribution 4.0 International License, which permits use, sharing, adaptation, distribution and reproduction in any medium or format, as long as you give appropriate credit to the original author(s) and the source, provide a link to the Creative Commons licence, and indicate if changes were made. The images or other third party material in this article are included in the article's Creative Commons licence, unless indicated otherwise in a credit line to the material. If material is not included in the article's Creative Commons licence and your intended use is not permitted by statutory regulation or exceeds the permitted use, you will need to obtain permission directly from the copyright holder. To view a copy of this licence, visit http://creativecommons.org/licenses/by/4.0/. The Creative Commons Public Domain Dedication waiver (http://creativeco mmons.org/publicdomain/zero/1.0/) applies to the data made available in this article, unless otherwise stated in a credit line to the data. 
Table 1 The definition of some concepts in this paper

\begin{tabular}{|c|c|}
\hline Classification & Definition \\
\hline Liver injury [3] & ALT and/or AST over $3 \times$ ULN, ALP, GGT, and/or TBIL over $2 \times$ ULN \\
\hline Hepatocellular [3] & elevated ALT and/or AST more than $3 \times$ ULN \\
\hline Cholestatic [3] & elevated ALP or GGT over twice the ULN \\
\hline Mixed (Abnormality) [3] & Both elevated ALT and/or AST more than $3 \times$ ULN, and elevated ALP or GGT over twice the ULN \\
\hline Cytokine Storm & $\begin{array}{l}\text { The inflammatory markers C-reactive protein (CRP), serum ferritin, LDH, D-dimer, IL-6 and IL-2 in } \\
\text { severe COVID-19 patients are significantly increased }\end{array}$ \\
\hline Mild cases of COVID-19 [4] & patient can present as common symptoms: fever, dry cough, fatigue, headache, sore throat \\
\hline Severe cases of COVID-19 [4] & $\begin{array}{l}\text { Patient who fits any one of the following condition: } \\
\text { 1. Respiratory rate } \geq 30 \text { breath/min } \\
\text { 2. } \mathrm{SpO}_{2} \leq 93 \% \\
\text { 3. } \mathrm{PaO}_{2} / \mathrm{FiO}_{2} \leq 300 \mathrm{mmHg}(1 \mathrm{mmHg}=0.133 \mathrm{kPa})\end{array}$ \\
\hline
\end{tabular}

study found that $41.0 \%$ and $5.0 \%$ of the 417 patients had abnormal liver function test and liver injury at admission. However after 2 weeks of hospitalization, patients with abnormal liver function tests and liver injury increased to $76.3 \%$ and $21.5 \%$ respectively. Bloom [5] also observed the same trend of liver biochemical reaction in patients with COVID-19. The ratio of patients with at least one abnormal liver biochemical index increased from 69 to 93\%. It can be seen that the incidence of abnormal liver function test gradually increased with the extension of observation time. Previous studies reported that the proportion of elevated ALT was 9.6-37.6\% [3, 6-9], the proportion of elevated AST was $14.8-36 \%$ [3, 6-10], the proportion of abnormal GGT was $13.0-24.4 \%[3,6]$, and the proportion of abnormal total bilirubin was $5.1-18 \%$ $[2,3,7,9]$. Generally speaking, incidence of abnormal liver function examination in hospitalized patients with COVID-19 ranges from 10.5 to $69 \%$ [3, 5, 11-13]. Most studies have shown that abnormal liver function tests are mainly caused by elevated AST and ALT, and elevated
AST was more common than ALT. Compared with AST and ALT, elevated GGT and total bilirubin are less common.

\section{Liver injury prone population}

A summary of the liver injury prone population is given in Table 2, which is discussed in detail below. Several studies have reported that the severe cases of COVID-19 were more likely to have severe liver injury compared to mild cases $[2,13,14]$. Male patients were more likely to have liver function injury than female $(\mathrm{P}<0.05)$ [7]. The analysis of 417 patients with COVID-19 in Shenzhen showed that the patients with abnormal liver function were older, had higher proportion of cough as the first symptom, higher BMI, greater proportion of male, had not contacted with SARS-CoV-2, and had more of underlying liver diseases(all $\mathrm{P}<0.05)$ [3]. Some studies showed that there was no significant difference in age, medication history and symptoms between the two groups [7]. A multicenter study in USA found that the proportion of

Table 2 Liver injury prone population

\begin{tabular}{|c|c|}
\hline Author & Liver injury prone population \\
\hline Guan [2], Mao [13], Henry [14] & Severe COVID-19 patients > Mild COVID-19 patients \\
\hline Xie [7] & $\begin{array}{l}\text { Male > Female; } \\
\text { The patients with severe lung disease; } \\
\text { But patients' age, previous medication history and symptoms without significant } \\
\text { difference }(P>0.05)\end{array}$ \\
\hline Mao [13] & $\begin{array}{l}\text { Hubei Province in China > other parts of China; } \\
\text { Severe COVID-19 Patients > Mild COVID-19 patients }\end{array}$ \\
\hline Cai [3] & $\begin{array}{l}\text { Aged; } \\
\text { Initial symptoms is cough; } \\
\text { Higher BMl; } \\
\text { Male; } \\
\text { Patients with underlying liver diseases; }\end{array}$ \\
\hline Zhang [6] & The patients with severe lung disease \\
\hline Singh [15] & Patients with underlying liver diseases $>$ Patients without underlying liver diseases \\
\hline
\end{tabular}


AST was more than 3 times higher than the upper limit of normal value in patients with underlying liver diseases than that in patients without underlying liver diseases. Other indicators such as increased GGT were more common in patients with underlying liver diseases, indicating that patients with underlying liver diseases (fatty liver or nonalcoholic fatty liver disease) were more likely to have abnormal liver function test than patients without underlying liver diseases [15]. Logistic regression analysis showed that the degree of lung lesions on CT was a predictor of liver dysfunction $(\mathrm{P}<0.05)$. Severe lung lesions were more likely to cause liver dysfunction [6]. Another study [16] showed that among the COVID-19 patients who received organ transplantation, the ICU admission rate was as high as $33.3 \%$, and $20 \%$ of patients died. It can be seen that the death risk of liver and kidney transplantation patients is increased.

\section{Possible mechanism of liver injury induced by COVID-19}

Figure 1 summarizes the possible mechanisms of liver injury, which will be discussed below.

\section{Direct damage}

Angiotensin-converting enzyme 2 (ACE2) is a key receptor of SARS-CoV-2 virus [17]. Xiaoqiang Chai et al. evaluated the cell-specific expression of the ACE2 receptor in healthy liver tissues and found that ACE2 was expressed in $2.6 \%$ of hepatocytes and $59.7 \%$ of cholangiocytes, suggesting that liver injury may be caused by direct viral invasion [18]. A recent study by Wu et al. found that half of COVID-19-infected patients who had completely cleared respiratory tract infections had virus shedding in their fecal specimens up to 11 days after viral detection in respiratory tract samples became negative [19]. This

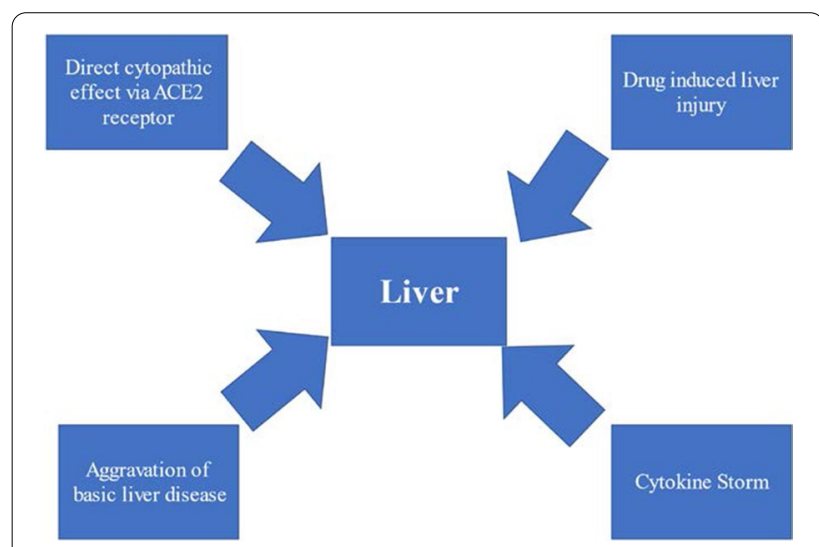

Fig. 1 Possible mechanism of liver injury induced by COVID-19 suggests that there may be viral replication in extrapulmonary sites (digestive tract, liver).

\section{Drug-induced liver injury}

Drugs for COVID-19 may cause liver damage. Some of these drugs, including lopinavir/ritonavir, rececivir, chloroquine, tocilizumab, mitifovir and traditional Chinese medicine, may have hepatic toxicity in some patients [20]. Some researchers [21] analyzed 148 cases of COVID-19 confirmed in Shanghai. The results showed that there were no significant difference in the pre hospital medication between the patients with normal liver function and those with abnormal liver function. However, the utilization rate of lopinavir/ritonavir in patients with new liver injury after admission was significantly higher than that in patients with normal hepatic function. Therefore, offtarget drug actions may be one of the causes of COVID19-related liver injury. It is suggested that monitoring the changes of liver function and timing of medication in patients with COVID-19 during hospitalization can better judge the causal relationship between drugs and liver injury.

\section{Cytokine Storm}

Immune mediated injury caused by severe inflammatory reaction after COVID-19 infection can also cause liver injury [22]. The inflammatory markers $\mathrm{C}$-reactive protein (CRP), serum ferritin, LDH, D-dimer, IL-6 and IL-2 in severe COVID-19 patients are significantly increased leading to a "cytokine storm" (see Table 1). Cytokine storm often leads to sudden deterioration of the patient's condition as the patient quickly enters the state of multiple organ failure, and the systemic inflammation caused by it can lead to secondary liver injury [23].

\section{Aggravation of underlying liver diseases}

The prevalence of chronic liver disease in patients with COVID-19 was reported in previous studies, and the overall prevalence was $2-11 \%[12,24]$. Studies have shown that obesity may aggravate the severity of COVID19 patients. Patients with metabolically related fatty liver disease have additional metabolic risk factors, which may be associated with more severe disease phenotype [25]. It is not known whether patients with underlying liver disease are more likely to be infected with COVID19, but $\mathrm{Da}[26]$ and others predicted that patients with alcohol use disorder (AUD) and alcohol-related liver disease (ALD) may be one of the most affected populations. The main reasons are that these patients cannot meet with doctors regularly, hospital resources transfer, social isolation, resulting in psychological decompensation, increased drinking or recurrence. 
In addition, the authors suggest that liver damage may be caused by viral reactivation of existing liver diseases. Patients with chronic liver diseases are more likely to suffer from COVID-19 related liver damage. Some biological drugs such as tocilizumab (IL-6 receptor blockade) and baricitinib (janus kinase inhibitor, might interrupt endocytosis of the virus and intracellular assembly of virus particles) may also cause $\mathrm{HBV}$ activation, leading to deterioration of liver function [20]. At present, the exact cause of liver injury in patients with COVID-19 is still unclear. However, it has been observed that the increase of liver enzymes in patients with COVID-19 is mostly mild and lasts for a short time. It is speculated that systemic inflammatory reaction and drug-induced are more likely.

\section{Clinical characteristics of liver injury in COVID-19 patients \\ Pathophysiological characteristics}

Liver biopsy specimens from patients with COVID19 showed moderate microvascular steatosis and mild lobular and portal vein activity [27]. Autopsy results of a dead COVID-19 patient showed mild infiltration of hepatic lobules, infiltration of small lymphocytes, sinusoidal expansion of central lobule, and patchy necrosis [28]. There was no obvious inflammatory cell infiltration around the portal vein and the terminal hepatic vein, which is basically consistent with the mode of acute liver injury.In other words, there is no cytoplasmic balloon like change, mallory glass like change, or extracellular fibrosis, and more serious histological changes such as obvious coagulation necrosis and severe cholestasis have not been seen [29].

\section{The characteristics, degree and time trend of liver enzyme elevation in patients with liver injury}

The situation of patients with liver injury from different studies are summarized in Table 3. which are detailed explanations of them. Among the 41 hospitalized patients first reported in Wuhan, China, 37\% of them had elevated AST. The average levels of ALT, AST and total bilirubin were 32.0 (21.0-50.0) U/L, 34.0 (26.048.0) U/L, and 11.7 (9.5-13.9) $\mu \mathrm{mol} / \mathrm{L}$ [10]. According to the biochemical analysis of 99 patients with COVID-19 infection in Wuhan area by Chen [9], the average level of ALT was 39.0 (22.0-53.0) U/L, and the average level of AST was 34.0 (26.0-48.0) U/L. The average level of total bilirubin was $15.1(7.3) \mu \mathrm{mol} / \mathrm{L}$, and liver enzymes were only slightly increased. Zhang [6] and others analyzed 115 cases of COVID-19 patients in Wuhan, and found that ALT was increased in 11 cases, and only 1 case was higher than $150 \mathrm{u} / \mathrm{L}$. In addition, AST in 17 cases was increased in the range of $40-120 \mathrm{U} / \mathrm{L}$; TBIL in 7 cases was increased in the range of $21-31.5 \mu \mathrm{mol} / \mathrm{L}$; ALP in 6 cases was increased ito $120-300 \mathrm{U} / \mathrm{L}$; GGT in 15 patients was increased, and GGT in 3 patients exceeded 142.5 $\mathrm{U} / \mathrm{L}$. Wang et al. reported that the levels of ALT (35 vs 23, $\mathrm{P}=0.007)$ and AST (52 vs $29, \mathrm{P}<0.001)$ in ICU patients were significantly higher than those in non ICU patients [30]. Filipe S. Cardoso reported the situation of liver injury in critically ill patients. During the 10 days of ICU observation, ALT and AST only slightly increased, and the highest value was no more than twice of the upper limit. However, with extended time, the increase of GGT became more and more obvious, reaching 3 times of the upper limit of normal value. The median peak value of GGT occurred 8 days after ICU admission. Generally speaking, liver injury was not serious, and late cholestasis was common [31]. Similar results were observed by Cai [3]. 417 patients with COVID-19 in Shenzhen were analyzed. It was found that most of the patients had abnormal liver test results within $1-2 \times$ the upper limit of normal value, and only a few $(<4 \%)$ patients had abnormal liver test results higher than $2 \times$ the upper normal value. GGT increased more significantly than other indicators, $12.71 \%$ of patients had 1-2 times the normal upper limit value, $1.2 \%$ of patients had $2-3$ times the normal upper limit value, 10 cases of $2.4 \%$ patients had more than 3 times the normal upper limit values. $\mathrm{Li}$ [8] and others observed 25 fatal cases in patients infected with COVID-19. Among these patients, the average levels of ALT and AST were 24 (16.5-46) U/L and 37 (29.5-57.5) $\mathrm{U} / \mathrm{L}$, and the liver function was only slightly abnormal, but almost all patients had lower albumin (32.8 (28.6-36.0) $\mu \mathrm{mol} / \mathrm{L}$. Bloom [5] and others evaluated the change trend of ALT and AST with time in 60 patients with COVID-19, and found that the change trend of ALT and AST was basically the same. However with more time, it could slightly increase, reaching the peak on the 9th day of admission, and then decreasing slowly, with the increase range not more than $40 \mathrm{U} / \mathrm{L}$. The comparison of the median of liver biochemical indexes between mild cases and severe cases at admission and at the peak of hospitalization is shown in Fig. 2. As can be seen from Fig. 2, in mild cases, the median changes of AST and ALT during admission and peak hospitalization were relatively small. In severe cases, AST and ALT at the peak of hospitalization were higher than those at admission. In addition, a retrospective analysis found that the percentage of mild cases in patients with elevated ALT and AST was $12.6 \%$, while the percentage of severe cases was $46.2 \%$. During the treatment period, $19 \%$ of the patients had elevated liver function parameters, but most of the patients had only mild and isolated elevation of ALT and AST, and most of the patients had normal liver indexes at discharge. However, patients with severe disease were 


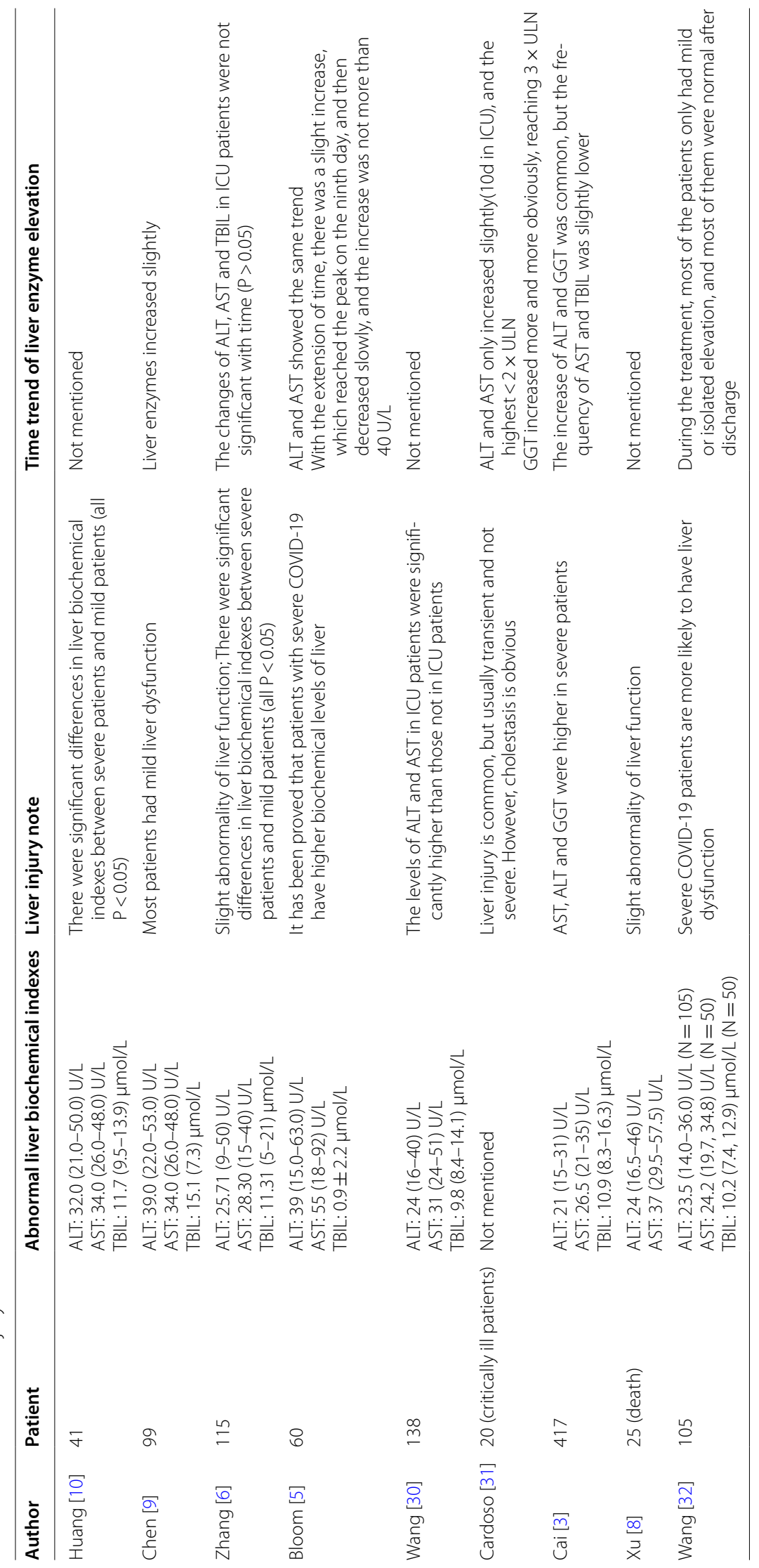




\section{Changes of the median of liver biochemical indexes}

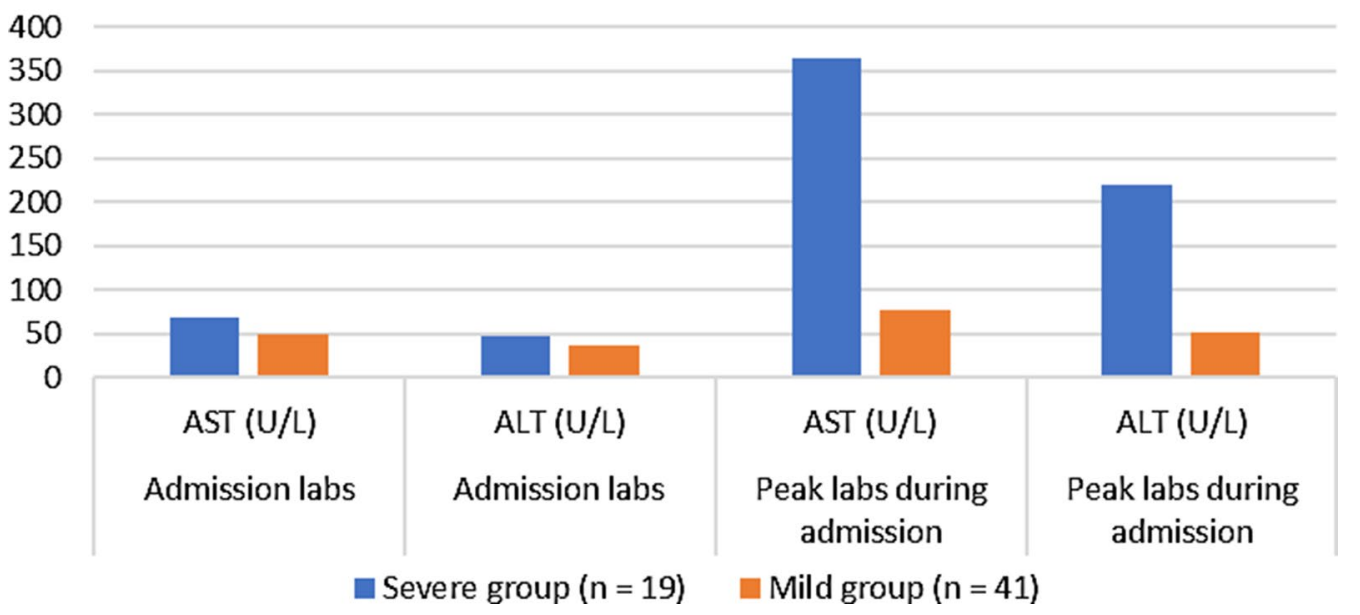

Fig. 2 Change of the median of liver biochemical indexs

more likely to have abnormal liver function [32]. Generally speaking [12], in mild cases of COVID-19, the increase of liver enzymes is usually mild, and severe liver damage is rare, lasting for a short time. Liver damage is usually transient and can be returned to normal without any special treatment. However, when severe liver damage occurs, hepatoprotective drugs are usually given to such patient, such as L-ornithine-L-aspartate [33].

\section{Effect of liver injury on prognosis of patients with COVID-19}

The meta-analysis conducted by Henry [14] and others tried to find the blood, biochemical and immune biomarkers related to the severity and mortality of COVID-19. The results showed that the biomarkers of inflammation, myocardial injury, liver and kidney function and coagulation function in severe and critical patients were significantly higher than those in nonsevere patients. It was suggested that liver injury may be related to severe COVID-19 infection. A retrospective analysis was conducted to compare the clinical characteristics of patients with and without liver function injury. The results showed that compared with patients without liver injury, the hospitalization time of patients with liver injury was significantly longer $(\mathrm{P}<0.05)[7]$. A multicenter retrospective cohort study found that abnormal AST was the most associated with the risk of death in patients with COVID-19 compared with other indicators of liver injury during hospitalization (HR 4.81-14.87, $\mathrm{P}<0.001$ ) [34]. In a multicenter study conducted by Singh [15], 2780 patients with COVID-19 were included. After adjusting for age, BMI, complications and other factors, patients with underlying liver disease had higher mortality (12\% vs $4 \%$, RR $3.0,95 \%$ CI $1.5-6.0)$ and hospitalization rate $(48 \%$ vs $36 \%$, RR $1.3(1.1,1.6)$. Compared to patients without NAFLD, patients with NAFLD had a higher risk of disease progression [6.6\% (5/126) vs $44.7 \%$ (34/76), $\mathrm{P}<0.001$ ] [35]. However, Bolin Wang et al. conducted a meta-analysis on 1558 patients with COVID-19 and found that hypertension, diabetes mellitus, COPD, cardiovascular disease and cerebrovascular disease were the main risk factors for the severity of COVID-19 patients, while there was no correlation between liver disease, malignant tumor or kidney disease and disease severity [36]. The prediction model established by Gong [37] and others showed that elderly patients, high serum LDH, C-reactive protein, coefficient of variation of red blood cell distribution width, blood urea nitrogen, direct bilirubin and low albumin were associated with severe COVID-19 infection (AUC 0.912, 95\% CI 0.846-0.978), sensitivity: $85.71 \%$, specificity: $87.58 \%$. Similarly, Huang [38] found that hypoalbuminemia can predict the prognosis of COVID-19 and is not related to age and complications. Multivariate regression analysis showed that hypoalbuminemia was an independent risk factor for death (OR 6.394, 95\% CI 1.315-31.092). Systematic review with meta-analysis showed that the increase of liver biochemistry during the first visit or illness is an important indicator of the severity of the disease. Low serum albumin indicates that this is a serious disease.The severity of elevated liver enzyme markers determines the outcome of COVID-19 [39]. Surprisingly, the incidence of liver injury is as high as $58-78 \%$ in the death cases of COVID-19 [40, 41]. In conclusion, there are many factors 
for poor prognosis of liver injury, which may be related to age ( $>60$ years old), severe COVID-19, basic diseases (hypertension, diabetes, cardiovascular disease, underlying liver diseases, etc.) and other related factors. If liver injury is combined with these factors, the patients may have a poor prognosis. Therefore, for spatients with severe COVID-19, require more in-depth monitoring or individualized treatment especially in elderly patients with underlying diseases or other complications.

\section{Management and treatment of liver injury}

Studies have suggested that all COVID-19 patients should be regularly monitored for liver biochemical indicators. So far, data on the safety of drugs used to treat COVID-19 patients with liver injury are still missing, and treatment is mostly based on experience [20]. In a consensus statement of the American Association for the Study of Liver Diseases (AASLD) expert panel, it was stated that (1) etiologies unrelated to COVID-19, including other viruses such as hepatitis $A$, hepatitis B and hepatitis $C$, should be considered when evaluating patients with COVID-19 and elevated liver biochemical reactions. (2) Considering other causes of elevated liver biochemical responses, including myositis (especially glutamic oxalacetic transaminase $>$ ALT), cardiac injury, ischemia, and cytokine release syndrome. (3) AST or ALT levels $>5 \times$ ULN may result in the exclusion of such patients in some drug studies, but abnormal liver biochemical reactions should not be contraindicated in studies of COVID-19 or in super-indication treatments (e.g., Redsivir, Toxicizumab, chloroquine, hydroxychloroquine). (4) All hospitalized patients with COVID-19, especially those treated with redesivir or tocilizumab, should be regularly monitored for liver biochemical indicators regardless of baseline values. (5) In patients with autoimmune hepatitis or liver transplantation, patients with elevated COVID-19 activity and liver biochemical reactions should not be considered to have sudden onset of disease or acute cellular rejection without biopsy confirmation. (6) Patients with cirrhosis, autoimmune hepatitis treated with immunosuppressive drugs, and post-transplant patients receiving immunosuppressive therapy should be considered at increased risk for severe COVID-19 and should be prioritized for testing [42]. Other recommendations include that ongoing HBV and HCV antiviral therapy should be continued, but initiation of antiviral therapy in HCV patients may need to be delayed. Nonemergency patients may postpone liver ultrasonography or liver biopsy. Strict treatment indications should be followed when immunosuppressive agents are initiated in patients with liver disease, such as autoimmune hepatitis $[\mathrm{AIH}]$ or graft rejection. Immunosuppressants should be continued in patients with AIH or transplantation.
In addition, over the course of the pandemic, it is worth mentioning that liver transplantation (LT) patients should need special clinical management. Most institutions suggest that LT patients should delay the operation, except for critically ill patients [43]. Currently, there are insufficient data to show the relationship between immunosuppressive therapy and COVID-19 in LT recipients. However, here are two different opinions. From the perspective of the Beijing liver transplantation working group [44], LT recipients with mild or no infection with SARS-CoV-2 should continue to receive immunosuppressive therapy, but LT recipients with moderate to severe infection with SARS-CoV-2 should be given a reduced calcineurin inhibitor treatment dosage. Also, in order to reduce the severity of pneumonia, LT patientsinfected with COVID-19 should be given short-term steroid therapy. On the contrary, the position statement in EASL-ESCMID recommended [43] that the dose of immunosuppressant drugs can be adjusted according to antiviral treatment regimens, because it is likely that the drugs in both regimens will interact with each other. During the pandemic, for patients undergoing liver transplantation, SARS-CoV-2 should be detected to prevent infection.

\section{Conclusion}

In conclusion, in COVID-19 disease, elevated liver enzymes are usually mild and generally recover without treatment. In clinical practice, we need to distinguish whether the onset of abnormal liver function occurs at diagnosis or during treatment.

\section{Abbreviations}

ALT: Alanine amino transaminase; AST: Aspartate amino transaminase; TBIL: Total bilirubin; GGT: $\gamma$-Glutamyl transpeptidase; ACE2: Angiotensin-converting enzyme 2; CoV: Coronaviruses; COVID-19: Coronavirus disease 2019; ICU: Intensive care unit; SARS-CoV-2: Severe Acute Respiratory Syndrome Coronavirus-2; USA: United States of America; WHO: World Health Organization; ULN: Upper limits of normal; HBV: Hepatitis B virus; HCV: Hepatitis C virus; LT: Liver transplantation; AlH: Autoimmune hepatitis.

\section{Acknowledgements \\ Not applicable.}

\section{Authors' contributions}

Dongdong Yu, Shengguang Yan, Xu Guang Guo, Yehao he, Guodong Zhu, Kewei Zhao and Shi Ouyang proposed the research idea and participated in its design. Dongdong Yu, Qingru Du, Shengguang Yan drafted the manuscript, translated it into English and contributed to the acquisition and interpretation of data together. Shi Ouyang provided critical review and substantially revised the manuscript. All authors read and approved the final manuscript.

\section{Funding}

This work was supported by the National Natural Science Foundation of China (Grant No. 81803884) and the scientific research project of Guangdong Provincial Bureau of traditional Chinese Medicine (20191215).

Availability of data and materials Not applicable. 


\section{Declarations}

Ethics approval and consent to participate

Not applicable.

\section{Consent to publication}

All authors approved the manuscript for publication.

\section{Competing interests}

The authors declare that they have no competing interests.

\section{Author details}

${ }^{1}$ Department of Traditional Chinese Medicine, The Fifth Affiliated Hospital of Guangzhou Medical University, Guangzhou 510150, China. ${ }^{2}$ Department of Infection Disease, The Fifth Affiliated Hospital of Guangzhou Medical University Guangzhou, Guangzhou 510150, China. ${ }^{3}$ School of Public Health, North China University of Science and Technology, Tangshan 063210, Hebei, China. ${ }^{4}$ Department of Clinical Laboratory Medicine, The Third Affiliated Hospital of Guangzhou Medical University, Guangzhou 510150, China. ${ }^{5}$ Department of Clinical Laboratory Medicine, The Fifth Affiliated Hospital of Guangzhou Medical University, Guangzhou 510150, China. ${ }^{6}$ Departments of Geriatrics and Oncology, Guangzhou First People's Hospital, Guangzhou 510180, China ${ }^{7}$ School of Medicine, South China University of Technology, Guangzhou, Guangdong, China. ${ }^{8}$ The Third Affiliated Hospital of Guangzhou University of Chinese Medicine, Guangzhou 510378, Guangdong, China. ${ }^{9}$ Department of Preventive Medicine, School of Public Health, Guangzhou Medical University, Guangzhou 510150, China.

Received: 12 December 2020 Accepted: 2 June 2021

Published online: 09 June 2021

\section{References}

1. Li G, Fan Y, Lai Y, Han T, Li Z, Zhou P, Pan P, Wang W, Hu D, Liu X, Zhang $\mathrm{Q}, \mathrm{Wu}$ J. Coronavirus infections and immune responses. J Med Virol. 2020:92(4):424-32.

2. Guan WJ, Ni ZY, Hu Y, Liang WH, Ou CQ, He JX, Liu L, Shan H, Lei CL, Hui DSC, Du B, Li LJ, Zeng G, Yuen KY, Chen RC, Tang CL, Wang T, Chen PY, Xiang J, Li SY, Wang JL, Liang ZJ, Peng YX, Wei L, Liu Y, Hu YH, Peng P, Wang JM, Liu JY, Chen Z, Li G, Zheng ZJ, Qiu SQ, Luo J, Ye CJ, Zhu SY, Zhong NS. Clinical characteristics of coronavirus disease 2019 in China. N Engl J Med. 2020;382(18):1708-20.

3. Cai Q, Huang D, Yu H, Zhu Z, Xia Z, Su Y, Li Z, Zhou G, Gou J, Qu J, Sun Y, Liu Y, He Q, Chen J, Liu L, Xu L. COVID-19: abnormal liver function tests. J Hepatol. 2020;73(3):566-74.

4. Handbook of prevention and treatment of the pneumonia caused by the novel coronavirus (2019-nCoV).

5. Bloom PP, Meyerowitz EA, Reinus Z, Daidone M, Gustafson J, Kim AY, Schaefer E, Chung RT. Liver biochemistries in hospitalized patients with COVID-19. Hepatology (Baltimore, Md). 2020;73:890-900.

6. Zhang Y, Zheng L, Liu L, Zhao M, Xiao J, Zhao Q. Liver impairment in COVID-19 patients: a retrospective analysis of 115 cases from a single centre in Wuhan city, China. Liver Int. 2020;40(9):2095-103.

7. Xie H, Zhao J, Lian N, Lin S, Xie Q, Zhuo H. Clinical characteristics of nonICU hospitalized patients with coronavirus disease 2019 and liver injury: a retrospective study. Liver Int. 2020:40(6):1321-6.

8. Hao GR, Li JK, Li S, Li KB, Zhang ZH, Li HE. Quantitative assessment of non-point source pollution load of PN/PP based on RUSLE model: a case study in Beiluo River Basin in China. Environ Sci Pollut Res Int. 2020:27(27):33975-89.

9. Chen N, Zhou M, Dong X, Qu J, Gong F, Han Y, Qiu Y, Wang J, Liu Y, Wei Y, Xia J, Yu T, Zhang $X$, Zhang L. Epidemiological and clinical characteristics of 99 cases of 2019 novel coronavirus pneumonia in Wuhan, China: a descriptive study. Lancet (London, England). 2020;395(10223):507-13.

10. Huang C, Wang Y, Li X, Ren L, Zhao J, Hu Y, Zhang L, Fan G, Xu J, Gu X, Cheng Z, Yu T, Xia J, Wei Y, Wu W, Xie X, Yin W, Li H, Liu M, Xiao Y, Gao H, Guo L, Xie J, Wang G, Jiang R, Gao Z, Jin Q, Wang J, Cao B. Clinical features of patients infected with 2019 novel coronavirus in Wuhan, China. Lancet (London, England). 2020;395(10223):497-506.
11. Zhu J, Ji P, Pang J, Zhong Z, Li H, He C, Zhang J, Zhao C. Clinical characteristics of 3062 COVID-19 patients: a meta-analysis. J Med Virol. 2020:92(10):1902-14.

12. Zhang C, Shi L, Wang FS. Liver injury in COVID-19: management and challenges. Lancet Gastroenterol Hepatol. 2020;5(5):428-30.

13. Mao R, Qiu Y, He JS, Tan JY, Li XH, Liang J, Shen J, Zhu LR, Chen Y, lacucci M, Ng SC, Ghosh S, Chen MH. Manifestations and prognosis of gastrointestinal and liver involvement in patients with COVID-19: a systematic review and meta-analysis. Lancet Gastroenterol Hepatol. 2020;5(7):667-78

14. Henry BM, de Oliveira MHS, Benoit S, Plebani M, Lippi G. Hematologic, biochemical and immune biomarker abnormalities associated with severe illness and mortality in coronavirus disease 2019 (COVID-19): a meta-analysis. Clin Chem Lab Med. 2020;58(7):1021-8.

15. Singh S, Khan A. Clinical characteristics and outcomes of coronavirus disease 2019 among patients with preexisting liver disease in the United States: a multicenter research network study. Gastroenterology. 2020;159(2):768-771.e3.

16. Malekhosseini SA, Nikoupour H, Gholami S, Shamsaeefar A, Arasteh P, Kazemi K, Dehghani M, Eghlimi H, Shahraki HR, Roozbeh J, Rezaianzadeh A, Nikeghbalian S. A report of 85 cases of COVID-19 and abdominal transplantation from a single center: what are the associated factors with death among organ transplantation patients. Transplantation. 2020;105:90-9.

17. Sarin SK. Fast, faster, and fastest: science on the run during COVID-19 drama"-"do not forget the liver. Hepatol Int. 2020;14(4):454-5.

18. Chai X, Hu L, Zhang Y, Han W, Lu Z, Ke A, Zhou J, Shi G, Fang N, Fan J, Cai J, Lan F. Specific ACE2 expression in cholangiocytes may cause liver damage after 2019-nCoV infection. bioRxiv (2020).

19. Wu Y, Guo C, Tang L, Hong Z, Zhou J, Dong X, Yin H, Xiao Q, Tang Y, Qu $X$, Kuang L, Fang $X$, Mishra N, Lu J, Shan $H$, Jiang G, Huang X. Prolonged presence of SARS-CoV-2 viral RNA in faecal samples. Lancet Gastroenterol Hepatol. 2020;5(5):434-5.

20. Sun J, Aghemo A, Forner A, Valenti L. COVID-19 and liver disease. Liver Int. 2020;40(6):1278-81.

21. Li J, Gong X, Wang Z, Chen R, LiT, Zeng D, Li M. Clinical features of familial clustering in patients infected with 2019 novel coronavirus in Wuhan, China. Virus Res. 2020:286:198043-4

22. Mehta P, McAuley DF, Brown M, Sanchez E, Tattersall RS, Manson JJ. COVID-19: consider cytokine storm syndromes and immunosuppression. Lancet (London, England). 2020;395(10229):1033-4.

23. Liu J, Li S, Liu J, Liang B, Wang X, Wang H, Li W, Tong Q, Yi J, Zhao L, Xiong L, Guo C, Tian J, Luo J, Yao J, Pang R, Shen H, Peng C, Liu T, Zhang Q, Wu J, Xu L, Lu S, Wang B, Weng Z, Han C, Zhu H, Zhou R, Zhou H, Chen X, Ye P, Zhu B, Wang L, Zhou W, He S, He Y, Jie S, Wei P, Zhang J, Lu Y, Wang W, Zhang L, Li L, Zhou F, Wang J, Dittmer U, Lu M, Hu Y, Yang D, Zheng X. Longitudinal characteristics of lymphocyte responses and cytokine profiles in the peripheral blood of SARS-CoV-2 infected patients. EBioMedicine. 2020:55:102763.

24. Mantovani A, Beatrice G, Dalbeni A. Coronavirus disease 2019 and prevalence of chronic liver disease: a meta-analysis. Liver Int. 2020;40(6):1316-20

25. Zheng KI, Gao F, Wang XB, Sun QF, Pan KH, Wang TY, Ma HL, Chen YP, Liu WY, George J, Zheng MH. Letter to the Editor: Obesity as a risk factor for greater severity of COVID-19 in patients with metabolic associated fatty liver disease. Metab Clin Exp. 2020;108:154244-5.

26. Da BL, Im GY, Schiano TD. COVID-19 hangover: a rising tide of alcohol use disorder and alcohol-associated liver disease. Hepatology (Baltimore, Md). 2020;72:1102-8.

27. Xu Z, Shi L, Wang Y, Zhang J, Huang L, Zhang C, Liu S, Zhao P, Liu H, Zhu L, Tai Y, Bai C, Gao T, Song J, Xia P, Dong J, Zhao J, Wang FS. Pathological findings of COVID-19 associated with acute respiratory distress syndrome. Lancet Respir Med. 2020;8(4):420-2.

28. Tian S, Xiong Y, Liu H, Niu L, Guo J, Liao M, Xiao SY. Pathological study of the 2019 novel coronavirus disease (COVID-19) through postmortem core biopsies. Mod Pathol. 2020;33(6):1007-14.

29. Li Y, Xiao SY. Hepatic involvement in COVID-19 patients: pathology, pathogenesis, and clinical implications. J Med Virol. 2020;92:1491-4.

30. Wang D, Hu B, Hu C, Zhu F, Liu X, Zhang J, Wang B, Xiang H, Cheng Z, Xiong Y, Zhao Y, Li Y, Wang X, Peng Z. Clinical characteristics of 138 
hospitalized patients with 2019 novel coronavirus-infected pneumonia in Wuhan. China Jama. 2020;323(11):1061-9.

31. Cardoso FS, Pereira R, Germano N. Liver injury in critically ill patients with COVID-19: a case series. Crit Care (Lond, Engl). 2020;24(1):190.

32. Wang Q, Zhao H, Liu LG, Wang YB, Zhang T, Li MH, Xu YL, Gao GJ, Xiong HF, Fan Y, Cao Y, Ding R, Wang JJ, Cheng C, Xie W. Pattern of liver injury in adult patients with COVID-19: a retrospective analysis of 105 patients. Mil Med Res. 2020;7(1):28.

33. Yang RX, Zheng RD, Fan JG. Etiology and management of liver injury in patients with COVID-19. World J Gastroenterol. 2020;26(32):4753-62.

34. Lei F, Liu YM, Zhou F, Qin JJ, Zhang P, Zhu L, Zhang XJ, Cai J, Lin L, Ouyang S, Wang X, Yang C, Cheng X, Liu W, Li H, Xie J, Wu B, Luo H, Xiao F, Chen J, Tao L, Cheng G, She ZG, Zhou J, Wang H, Lin J, Luo P, Fu S, Zhou J, Ye P, Xiao B, Mao W, Liu L, Yan Y, Liu L, Chen G, Li H, Huang X, Zhang BH, Yuan Y. Longitudinal association between markers of liver injury and mortality in COVID-19 in China. Hepatology (Baltimore, Md). 2020;72(2):389-98.

35. Ji D, Qin E, Xu J, Zhang D, Lau G. Implication of non-alcoholic fatty liver diseases (NAFLD) in patients with COVID-19: a preliminary analysis. J Hepatol. 2020;73:451-3.

36. Wang $B$, Li R, Lu Z, Huang Y. Does comorbidity increase the risk of patients with COVID-19: evidence from meta-analysis. Aging. 2020;12(7):6049-57.

37. Jiao G, Jingyi $O$, Xueping $Q$, Yusheng J, Yaqiong C, Lianxiong Y, Jing C, Mingkai T, Wenxiong $X$, Fang Z. A tool for early prediction of severe coronavirus disease 2019 (COVID-19): a multicenter study using the risk nomogram in Wuhan and Guangdong. China, Clin Infect Dis. 2020;71:833-40.

38. Huang J, Cheng A, Kumar R, Fang Y, Chen G, Zhu Y, Lin S. Hypoalbuminemia predicts the outcome of COVID-19 independent of age and co-morbidity. J Med Virol. 2020;92:2152-8.
39. Kulkarni AV, Kumar P, Tevethia HV, Premkumar M, Arab JP, Candia R, Talukdar R, Sharma M, Qi X, Rao PN, Reddy DN. Systematic review with metaanalysis: liver manifestations and outcomes in COVID-19. Alim Pharmacol Therap. 2020;52(4):584-99.

40. Zhang B, Zhou X, Qiu Y, Feng F, Feng J, Jia Y, Zhu H, Hu K, Liu J, Liu Z. Clinical characteristics of 82 death cases with COVID-19. MedRxiv. 2020;3:1279.

41. Huang $Y$, Zhou H, Yang R, Xu Y, Feng X, Gong P, Clinical characteristics of 36 non-survivors with COVID-19 in Wuhan, China. MedRxiv (2020).

42. Fix OK, Hameed B, Fontana RJ, Kwok RM, McGuire BM, Mulligan DC, Pratt DS, Russo MW, Schilsky ML, Verna EC, Loomba R, Cohen DE, Bezerra JA, Reddy KR, Chung RT. Clinical best practice advice for hepatology and liver transplant providers during the COVID-19 pandemic: AASLD Expert Panel Consensus Statement. Hepatology (Baltimore, Md). 2020;72(1):287-304.

43. Sahin TT, Akbulut S, Yilmaz S. COVID-19 pandemic: its impact on liver disease and liver transplantation. World J Gastroenterol. 2020;26(22):2987-99.

44. Liu H, He X, Wang Y, Zhou S, Zhang D, Zhu J, He Q, Zhu Z, Li G, Sun L, Wang J, Cheng G, Liu Z, Lau G. Management of COVID-19 in patients after liver transplantation: Beijing working party for liver transplantation. Hepatol Int. 2020;14(4):432-6.

\section{Publisher's Note}

Springer Nature remains neutral with regard to jurisdictional claims in published maps and institutional affiliations.
Ready to submit your research? Choose BMC and benefit from:

- fast, convenient online submission

- thorough peer review by experienced researchers in your field

- rapid publication on acceptance

- support for research data, including large and complex data types

- gold Open Access which fosters wider collaboration and increased citations

- maximum visibility for your research: over 100M website views per year

At BMC, research is always in progress.

Learn more biomedcentral.com/submissions 